with a hepatoma who had been taking hormone replacement therapy and in whom serum markers were absent.

Though the chances of a woman taking the pill developing a hepatocellular carcinoma are low, the possibility needs to be considered in any woman with a long history of contraceptive use who develops new symptoms of right upper or central abdominal pain or in whom unexplained hepatomegaly is found. Further investigation by the non-invasive technique of ultrasound together with liver function tests should be enough to indicate the likelihood of a tumour of the liver.

We thank Professor M Vessey for the data on control women, obtained from his studies on breast cancer, and also for his comments on the manuscript.

\section{References}

1 Mettlin L, Natarajan N. Studies on the role of oral contraceptive use in the etiologv of benign and malignant liver tumors. F Surg Oncol 1981;18:73-85.

2 Klatskin G. Hepatic tumors-possible relationship to use of oral contraceptives. Gastroenterology 1977;73:386-94.

3 Christopherson WM, Mays ET, Barrows GH. Liver tumours in young women. In: Fenoglis CM, Wolff R, eds. Progress in surgical pathology. Vol 2. New York: Masson Publishing UK, 1980:187-205

4 Mays ET, Christopherson W. Hepatic tumors induced by sex steroids. Semin Liver Dis 1984;4:147-57.

5 MacCormack KA, Nathan SK, Covey W, et al. Oral contraceptive use. NY State $\mathcal{f}$ Med 1977;72:200-2.

6 Vana J, Murphy GP, Aronoff BL, Baker HW. Primary liver tumors and oral contraceptivesresults of a survev. JAMA 1977;238:2154-8.

7 Edmondson HA, Henderson B, Benton B. Liver cell adenomas associated with the use of the oral contraceptive. N Engl f Med 1976;294:470-2.
8 Rooks JB, Ory AW, Ishak KG, et al. Epidemiology of hepatocellular adenoma. JAMA 1979;242:644-8.

9 Sricker BH, Spoelestra P. Drug induced hepatic injury. In: Dukes MNG, ed. Drug induced disorders. Vol I. Amsterdam: Elsevier, 1985:237-41.

10 Davis $M$, Portmann B, Searle $M$, Wright $\mathbf{R}$, Williams $\mathbf{R}$. Histological evidence of carcinoma in a hepatic tumour associated with oral contraceptives. $\mathrm{Br}$ Med $\mathrm{f}$ 1975;iv:496-8.

1 Tesulk H, Lawrie J. Hepatocellular adenoma-its transition to carcinoma in a user of oral contraceptive. Archives of Pathology 1981;105:296-9.

12 Christopherson WM, Mays ET, Barrows G. Hepatocellular carcinoma in young women on oral contraceptives. Lancet 1978; ii:38-40.

13 Henderson BE, Preston-Martin S, Edmondson HA, Peters RL, Pike MC. Hepatocellular carcinoma associated with the use of oral contraceptives. Br f Cancer 1983;48:437-40.

14 Forman D, Doll R, Peto R. Trends in mortality from carcinoma of the liver and use of oral contraceptives. Br $\mathcal{F}$ Cancer 1983:48:349-54

15 Goodman ZD, Ishak GI. Hepatocellular carcinoma in women-probable lack of etiologic association with oral contraceptive steroids. Hepatology 1982;2:440-4.

16 Neuberger J, Portmann B, Nunnerley H, et al. Oral contraceptive associated liver tumours. Lance $1980 ;$; $273-6$.

17 Vessey M, Baron J, Doll R, et al. Oral contraceptives and breast cancer: final report of an epidemiological study. Br $\mathcal{F}$ Cancer 1983;47:455-62.

18 McPherson K, Neil A, Vessey M, Doll R. Oral contraceptives and breast cancer. Lancet 1983;ii:1414-5.

19 Adelcreutz $\mathrm{H}$, Tenhunen $\mathrm{R}$. Some aspects of the interaction between natural and synthetic female sex hormone and the liver. Am $\mathcal{F}$ Med 1970;49:630-48.

20 Yager JD. Yager R. Oral contraceptive steroids as promoters of hepatocarcinogenesis in female Sprague Dawley rats. Cancer Res 1980;40:3680-5.

21 Wanless IR, Medcine D. Role of estrogens as promoters of hepatic neoplasia. Lab Invest 1982;46:313-6.

22 Committee on the Safety of Medicines. Carcinogenicity tests of oral contraceptives. London: HMSO 1972.

23 Goldfarb S. Sex hormones and hepatic neoplasia. Cancer Res 1976;36:2584-8.

24 Irey NS, Manion WC, Taylor HB. Vascular lesions in women taking oral contraceptives. Archives of Pathology 1970;73:386-94

25 Trichopolous D, MacMahon B, Sparros L, et al. Smoking and hepatitis B negative primary hepatocellular carcinoma. Foumal of the National Cancer Institute 1980;65:111-4.

26 Brechot C, Nalpas B, Courouce AM, et al. Evidence that hepatitis B virus has a role in liver cell carcinoma in alcoholic liver disease. $N$ Engl $\mathcal{F}$ Med 1982;306:1384-7.

(Accepled 17 fanuary 1986)

\title{
Cancer of the liver and the use of oral contraceptives
}

\author{
D FORMAN, T J VINCENT, R DOLL
}

\begin{abstract}
A case-control study of the use of oral contraceptives was conducted among women certified as having died from cancer of the liver in the period $1979-82$ and in the age range $20-44$ years. An age matched group of women who died from other causes, not related to use of oral contraceptives, in the same period were used as controls. Information about use of oral contraceptives was obtained from the general practitioners' notes for both cases and controls. Information was obtained for 30 women with histologically confirmed liver cancer, 19 with hepatocellular carcinoma and 11 with cholangiocarcinoma, and for 147 controls. The results were analysed after adjusting for age at diagnosis and year of birth and showed that use of oral contraceptives was associated with a significantly $(p<0.05)$ raised relative risk for hepatocellular carcinoma of 3.8 (95\% confidence interval 1.0 to 14.6) and use for eight years or more was associated with a significantly $(p<0.01)$ increased relative risk of $20.1(2.3$ to 175.7). There were no apparent increases in risk for cholangiocarcinoma. Despite the small number of cases in this study and the methodological problems in assessing use of oral contra-
\end{abstract}

\footnotetext{
Imperial Cancer Research Fund, Cancer Epidemiology and Clinical Trials Unit, Gibson Building, Radcliffe Infirmary, Oxford

D FORMAN, PHD, research fellow

T J VINCENT, BSC, research officer

R DOLL, FRS, FRCP, FFCM, honorary consultant

Correspondence to: Dr Forman.
}

ceptives from general practitioners' notes, the results were consistent with other similar studies. Although in the United Kingdom primary liver cancer remains an exceptionally rare disease, especially in young women, further research on the role of oral contraceptives is needed in those countries where it is a much more common disease.

\section{Introduction}

The evidence that oral contraceptives may cause primary hepatocellular carcinoma in women rests almost entirely on anecdote or evidence from uncontrolled studies. Nevertheless, the number of cases of malignant liver tumours in young women taking oral contraceptives, based on individual reports, ${ }^{1}$ and more systematic surveys, ${ }^{2-4}$ continues to rise. Over 100 such cases have now been reported, and in England and Wales national mortality rates show a slight increase for this rare disease in women under the age of 50 since the mid-1960s when the use of oral contraceptives became widespread.' Several abnormal characteristics associated with the pathology and natural history of hepatocellular carcinoma in young users of oral contraceptives have also been noted. The tumours usually occur in non-cirrhotic livers, ${ }^{3}$ without associated hepatic fibrosis $^{3}$ or raised $\alpha$ fetoprotein concentrations. ${ }^{36}$ This evidence, together with the occasional reports of malignancy progressing from benign adenoma, ${ }^{78}$ which is certainly associated with the use of oral contraceptives, ${ }^{9}$ suggests that there could be a specific group of liver carcinomas related to oral contraceptives.

To date there has been only one published case-control study specifically designed to investigate this question, ${ }^{10}$ and this was 
based on the experience of 11 women with the disease. Because of the rarity of primary liver cancer, especially in women likely to take oral contraceptives, any study would have to draw on a large population to identify cases. Accordingly, we report here a study in which all women in England and Wales certified as having died from primary liver cancer between the ages of 20 and 44 over the period 1979 to 1982 were matched with controls and the respective histories of use of oral contraceptives investigated.

\section{Methods}

Draft death entries were obtained from the Office of Population Censuses and Surveys for all women aged between 20 and 44 years who died in the period 1979 to 1982 , with the main cause of death given as liver cancer (International Classification of Diseases (9th revision) code 155). This chronic liver disease that might be regarded as predisposing to the development of cancer (that is, patients with chronic active hepatitis or alcoholic cirrhosis). Our group was, therefore, limited to patients with primary cancer in non-cirrhotic livers. These cases and all the controls were then stratified by age at diagnosis (or at death for women killed in road traffic accidents) in two year groupings (20-21, 22-23, 24-25, 26-27, 28-29, 30-31, $32-33,34-35,36-37,38-39,40-41,42-43$, and 44$)$ and year of birth essentially in five year groupings (1934-9, 1940-4, 1945-9, 1950-4, 1955-9, and 1960-1). Relative risks were calculated, using a logistic regression model, for different periods of use of oral contraceptives up until one year before diagnosis (or one year before death for controls who died in road traffic accidents). The duration of use used in the calculations was the minimum period for which evidence was available in the general practitioners' notes that oral contraceptives had been prescribed. In many cases the only information available from the notes was the starting date for particular prescriptions. If these were six months or less apart then it was assumed that this represented a period of continuous use, and all such periods were added together. For

TABLE I-Identification of cases and controls

\begin{tabular}{|c|c|c|c|c|c|c|c|c|c|c|}
\hline \multirow[b]{2}{*}{ Year of death: } & \multicolumn{5}{|c|}{ Cases } & \multicolumn{5}{|c|}{ Controls } \\
\hline & 1979 & 1980 & 1981 & 1982 & Total & 1979 & 1980 & 1981 & 1982 & Total \\
\hline No of certified deaths & 22 & 23 & 17 & 28 & 90 & 44 & 46 & 34 & 113 & 237 \\
\hline Non-resident in LK & 1 & 3 & 0 & 1 & 5 & 0 & 2 & 1 & 1 & 4 \\
\hline FPC unable to trace patient's notes & 16 & 7 & 3 & 2 & 28 & 41 & 13 & 7 & 13 & 74 \\
\hline GP refused to cooperate & 1 & 2 & 5 & 3 & 11 & 2 & 3 & 0 & 7 & 12 \\
\hline Adequate information obtained & 4 & 11 & 9 & 22 & 46 & 1 & 28 & 26 & 92 & 147 \\
\hline
\end{tabular}

includes all certifications of hepatocellular carcinoma (155.0), cholangiocarcinoma (155.1), and liver cancer, unspecified as primary or secondary (155.2). Deaths from specified secondary liver cancer or from benign liver tumours were excluded. We also obtained draft death entries for women who had died of other diseases to use as a control group. These women were matched to the women with liver cancer by year of death and five year age group (20-24, 25-29, 30-34, 35-39, 40-44). For the control group we selected women with causes of death for which survival time after diagnosis is quite short and which were unlikely to be associated with use of oral contraceptives. Thus for each patient with liver cancer two controls were selected with a certification of cancer of the kidney (ICD 189), cancer of the brain (191), or acute myeloid leukaemia (205). For 1982 only each patient who had died from cancer of the liver was matched to two further controls who had died as a result of road traffic accidents.

The family practitioner committees responsible for the areas where the deaths of cases and controls were certified were then asked for the names of the general practitioners with whom the women were registered. When any committee had no trace of the patients the details were sent to the National Health Service Central Register in Southport to establish whether the patients were normally resident in the areas of other committees. All general practitioners identified in this way were then contacted and asked either to complete a questionnaire about the patient, having recalled the notes from the family practitioner committee, or to give us permission to obtain the notes and complete the questionnaire.

The questionnaire asked primarily for details of use of oral contraceptives. In addition, information was sought about other diseases, use of hormones apart from oral contraceptives, and, if available, smoking, occupation, and other demographic details. The general practitioners were asked to list all prescriptions for oral contraceptives and as much information as possible about starting date, duration of the prescription, repeat prescriptions, etc.

For cases of liver cancer, additional information was obtained by sending a further questionnaire to the hospitals where the patients were treated. This was to establish that the diagnosis on the death certificate was confirmed by the pathology (including postmortem pathology) and also to ascertain whether there was any evidence of infection with hepatitis virus or cirrhosis in the liver. In cases where inquests had been held we also obtained copies of the coroner's report, again in order to check the pathology. Although some additional inquiries also produced further information about the use of oral contraceptives, this was not used in subsequent analysis as comparable data were not available for controls.

Cases and controls were excluded if we were unable to identify or obtain a response from their recorded general practitioner. After the information from the hospital and the coroner had been reviewed cases were divided into three groups: those with a confirmed primary liver cancer (hepatocellular carcinoma), those with confirmed cholangiocarcinoma, and all others. For the purposes of our study we included only cases in the first and second groups and excluded from these groups cases in which there was evidence of prescriptions more than six months apart no assumption was made regarding a period of use, thus we knew that some of the women had taken oral contraceptives, but the minimum duration was unknown. For the purposes of the analysis these women were categorised with those who had used oral contraceptives for less than four years. Women for whom there was no record of a prescription of oral contraceptives in the general practitioners' notes were classified as never having used them.

\section{Results}

In all we received $90 \mathrm{draft}$ death entries for women with liver cancer and 237 for controls from the Office of Population Censuses and Surveys. Of these, five and four, respectively, were for women not resident in the United Kingdom and not registered with a general practitioner in this country. The family practitioner committees identified the general practitioner for 57 cases and 159 controls, but 11 and 12 of these general practitioners, respectively, either refused to participate in the study or would not reply to our letter (or to two subsequent letters). This left 46 cases and 147 controls about whom we obtained information. These are tabulated by year of death in table I.

We classified cause of death for the 46 cases using the draft death entries and after our own review of the hospital notes or coroner's report, or both. Of the 30 certified cases of hepatocellular carcinoma, two were in fact cholangiocarcinomas and seven did not have an established primary site in the liver. One of the 10 cholangiocarcinomas was also not a proved primary tumour, and three cases certified as unspecified primary or secondary cancer were in fact genuine cases of hepatocellular carcinoma. We were therefore left with 35 confirmed cases of primary liver cancer, of which 24 were hepatocellular carcinomas. Five more cases of hepatocellular carcinoma were excluded from analysis as two had chronic active hepatitis and two severe alcoholic disease and associated cirrhosis. The fifth patient was excluded from this group as she was reported to suffer from a congenital condition (Down's syndrome) that might have prejudiced the prescription of oral contraceptives. Table II lists the 30 remaining cases and the 147 controls by age at diagnosis and specific cause of death.

Table III shows the proportion of women among the cases and controls who had been recorded as using oral contraceptives. The group of women with hepatocellular carcinoma as cause of death contained a greater proportion of users of oral contraceptives than the group of cases of cholangiocarcinoma or any of the control groups. The four control groups all had similar proportions of women who had used oral contraceptives, although the proportion was slightly smaller among women who had died of cancer of the kidney or acute myeloid leukaemia and greater among women who had died in traffic accidents. Although the absolute numbers are very small, the proportion of women with hepatocellular carcinoma who had used

\section{,

.

,

. . .

.


TABLE II-Cases and controls by age at diagnosis

\begin{tabular}{|c|c|c|c|c|c|c|}
\hline \multirow[b]{2}{*}{ Cause of death } & \multicolumn{6}{|c|}{ Age (years) } \\
\hline & $<25$ & $25-9$ & $30-4$ & $35-9$ & $40-4$ & Total \\
\hline \multicolumn{7}{|c|}{ Cases } \\
\hline Hepatocellular carcinoma & 4 & 1 & 4 & 4 & 6 & 19 \\
\hline Cholangiocarcinoma & 1 & 1 & 1 & 4 & 4 & 11 \\
\hline \multicolumn{7}{|c|}{ Controls } \\
\hline All deaths & 24 & 20 & 18 & 27 & 58 & 147 \\
\hline Kidney cancer & 2 & 1 & 4 & 5 & 8 & 20 \\
\hline Brain cancer & 9 & 7 & 6 & 12 & 20 & 54 \\
\hline Acute myeloid leukaemia & 6 & 6 & 3 & 5 & 10 & 30 \\
\hline Road traffic accidents & 7 & 6 & 5 & 5 & 20 & 43 \\
\hline
\end{tabular}

tion equivalent to that of a combined oral contraceptive the exposure was included in the risk analysis. Table $\mathrm{V}$ shows the other hormones used by the women.

\section{Discussion}

The results presented in this paper indicate a risk of primary liver cancer associated with use of oral contraceptives. The risk is specifically associated with hepatocellular carcinoma and is largely confined to women who have used oral contraceptives for eight or more years. The very small number of women with hepatocellular carcinoma included in this analysis makes the estimation of the

TABLE III-No (\%) of cases and controls by duration ${ }^{\star}$ of use of oral contraceptives, as recorded in general practitioner's notes

\begin{tabular}{|c|c|c|c|c|c|}
\hline Cause of death & Never used & Ever used & $<4$ yearst & $4-7$ years & $\geqslant 8$ years \\
\hline $\begin{array}{l}\text { Hepatocellular carcinoma } \\
\text { Cholangiocarcinoma }\end{array}$ & $\begin{array}{l}+21 \cdot 0 \\
8(72 \cdot 7)\end{array}$ & $\begin{array}{c}\text { Cases } \\
1579 \cdot 0 \\
3(27 \cdot 3\end{array}$ & $\begin{array}{l}8(42 \cdot 1) \\
1(9 \cdot 1)\end{array}$ & $\begin{array}{l}4(21 \cdot 0) \\
2(18 \cdot 2)\end{array}$ & $\begin{array}{l}3(15 \cdot 8) \\
0\end{array}$ \\
\hline $\begin{array}{l}\text { All deaths } \\
\text { Kidney cancer } \\
\text { Brain cancer } \\
\text { Acute myeloid leukaemia } \\
\text { Road traffic accidents }\end{array}$ & $\begin{array}{l}68+6 \cdot 3 \\
11(55 \cdot 0 \\
25(46 \cdot 3) \\
16 \quad 53 \cdot 3 \\
16 \quad 37 \cdot 2\end{array}$ & $\begin{array}{r:r}\text { Controls } \\
79 & 53 \cdot 7 \\
9 & 45.0 \\
29 & 53 \cdot 7 \\
14 & +6.7 \\
27 & 62.8\end{array}$ & $\begin{array}{rl}56 & 38 \cdot 1 \\
6 & 30 \cdot 0 \\
24 & 44 \cdot 4 \\
8 & 26 \cdot 7 \\
18 & 41 \cdot 9\end{array}$ & $\begin{array}{rl}19 & 12 \cdot 9) \\
2 & (10 \cdot 0) \\
3 & 5 \cdot 6) \\
6 & 20 \cdot 0) \\
8 & 18 \cdot 6\end{array}$ & $\begin{array}{ll}4 & (2 \cdot 7) \\
1 & 5 \cdot 0 \\
2 & (3 \cdot 7) \\
0 & \\
1 & 2 \cdot 3\end{array}$ \\
\hline
\end{tabular}

*Duration of use recorded in GP notes up until one vear before date of diagnosis for cases and cancer controls or one vear before death for traffic accident controls.

†Women with prescriptions for oral contraceptives in their notes but insufficient evidence that they had used them for at least four vears are also included in this category.

TABLE IV-Estimated relative risks of primary liver cancer associated with use of oral contraceptives after adjustment for age at diagnosis and year of hirth

\begin{tabular}{lcc}
\hline \multicolumn{1}{c}{ Duration of use } & Hepatocellular carcinoma & Cholangiocarcinoma \\
\hline Never used & $1 \cdot 0$ & $1 \cdot 0$ \\
Ever used & $3 \cdot 8^{\star}$ & $0 \cdot 3$ \\
$4+$ vears & $3 \cdot 0$ & $0 \cdot 1$ \\
$4-7$ vears & $+\cdot 0$ & $0 \cdot 9$ \\
28 vears & $20 \cdot 1^{\star \star}$ & $0 \cdot 8 \cdot$ \\
7 For trend & $7 \cdot 74^{\star \star}$ & \\
\hline
\end{tabular}

${ }^{*} \mathrm{p}<0 \cdot 05,{ }^{* *} \mathrm{p}<0 \cdot 01$

TABLE V-Exposure of cases and controls to non-contraceptice hormones. Topical steroids excluded

\begin{tabular}{lcc}
\hline & Cases & Controls \\
\hline Progestogens & 1 & 10 \\
Fertility drugs & 0 & 5 \\
Diethyistilboestrol & 1 & 5 \\
Other oestrogens & 1 & 1 \\
Androgens & 0 & 0 \\
Anti-inflammatory drugs: & 2 & 2 \\
$\quad$ Prednisolone & 0 & \\
\hline
\end{tabular}

oral contraceptives for eight years or more $(15 \cdot 8 \%)$ was substantially greater than the proportion of controls who had done so $(2 \cdot 7 \%)$. There was no such difference in the category of four years of use or less $(42.1 \% v 38 \cdot 1 \%)$, although there was a slight difference in the category of four to seven years of use $(21.0 \% v 12.9 \%)$. This information is presented in terms of relative risks associated with different periods of use of oral contraceptives in table IV after adjustment for age at diagnosis and year of birth. The $20 \cdot 1$-fold risk of hepatocellular carcinoma associated with long term use of oral contraceptives is highly significant $(p<0.01)$ but has a very wide $95 \%$ confidence interval of $2 \cdot 3$ to $175 \cdot 7$. The risk of hepatocellular carcinoma associated with any use of oral contraceptives is $3.8(p<0.05)$, with $95 \%$ confidence intervals of $1 \cdot 0-14 \cdot 6$. None of the other relative risks were significant.

Cases and controls were exposed to a wide range of hormones other than oral contraceptives (excluding topical steroids). Where these had a formula- relative risk very imprecise and this is reflected in the wide confidence interval for the risk estimates. Nevertheless, the results show a significant trend, and the risk associated with long term use is highly significant. This study is therefore consistent with the previous case-control study ${ }^{11}$ and with the reported analysis of cases at a major referral centre," which included three patients with hepatocellular carcinomas classified as such in this study (two who did not use oral contraceptives and one who had used them for more than eight years). The exclusion of these patients from the analysis, however, had no appreciable effect on the relative risk estimates.

We encountered three major methodological problems in conducting this study-namely, identification of patients' general practitioners, selection of controls, and validation of the information. The use of death certificates as the primary source of information about cases creates difficulties for rare diseases, when it is desirable to use certifications from two or three vears after death in order to increase numbers. Although family practitioner committees have a statutory obligation to store general practitioners' records for three years after death, they often have great difficulty in tracing records more than one year after death. This is evident in the failure to trace records for patients and controls who died in 1979 and 1980 , seen in table I. Those who died in 1981 and 1982 were traced in the year after death, and the proportion in this group with identified general practitioners' notes was high $87 \%$ and $85 \%$ for cases and controls, respectively, compared with $40 \%$ and $38 \%$ for $1979-80$ ). Once general practitioners had been identified there was the additional problem of their refusing to cooperate, usually by failing to answer letters rather than direct refusal. There was a greater tendency for general practitioners of patients with liver cancer to refuse (11 out of $57(19 \%)$ ) than for those of controls (12 out of 159 $(7 \cdot 5 \%))$. This could represent a source of positive bias but only if a refusal from a general practitioner of a patient with liver cancer was associated with a tendency not to prescribe oral contraceptives.

Accuracy of certification also presents problems. Liver cancer has always been associated with miscertification due to a failure to distinguish primary liver tumours from metastases from other sites (R Doll, D Zaridze, unpublished observations). It has been assumed that this misclassification would be more prevalent in elderly people because of less intensive postmortem examinations. 
Of the 30 certified hepatocellular carcinomas in young women that we investigated, however, nine were classified wrongly, and of all the 46 deaths attributed to liver cancer not secondary, 15 were wrongly classified. Certification of primary liver cancer is therefore likely to be inaccurate in as many as one in three cases, even in women under 45 years of age.

The choice of appropriate controls to compare with cases who have died is a methodological problem about which there has been much discussion. ${ }^{12}{ }^{13}$ In this study we decided to use dead controls. However, selecting causes of death with acute symptoms, short survival time, and no known association with use of oral contraceptives is not straightforward for women in this age group. There is always the possibility that any one of the four causes chosen might have some, as yet undetected, association with oral contraceptives, however the relative consistency of patterns of use of oral contraceptives in the different control groups is evidence against this. Nevertheless, death in the 20-44 age group is an exceptional occurrence in developed countries, and the assumption that dead controls are truly representative of the general population has to be treated cautiously. The advantage of our control group was that the likelihood of an information ascertainment bias was much reduced, and data about cases and controls were obtained in exactly the same way and are directly comparable. Another means of obtaining controls, considered for this study, would have been to select women randomly from the lists of the cases' general practitioners. Although this would have matched for general practitioners' prescribing patterns, we would have had to rely on the general practitioners or their staff choosing the controls and extracting information about them without any bias. Occasional mistakes are made with such a protocol-for example, controls may be chosen only if they have used oral contraceptives, and with a small study this may dramatically affect the results. ${ }^{14}$ In these circumstances using dead controls was thought to be preferable.

Finally, there is the problem of the use of general practitioners' notes to obtain information about use of oral contraceptives. General practitioners' notes are deficient in two ways. Prescriptions for oral contraceptives by the general practitioner are often noted without any indication of how long the prescription is for or any follow up information showing whether the prescription has actually been used. Secondly, prescriptions made by agencies or clinics other than the general practitioner rarely appear in the notes. ${ }^{15}$ This means that the notes severely underrepresent the true extent of use of oral contraceptives and will occasionally classify women who have obtained all their prescriptions from other agencies as never having used oral contraceptives. A survey of general practitioners' information compared with detailed structural interviews of a group of 83 women showed that such categorical misclassification occurred in $10 \%$ of cases and that in another 33\% general practitioners' notes underestimated use by more than two years ( T J Vincent, J B Crossley, unpublished results). Our estimates of use of oral contraceptives are therefore, in absolute terms, undoubtedly wrong. There is no reason, however, why there should be a reporting difference between cases and controls, although this is possible.

General practitioners' notes also provide little information about variables that may be confounding factors. Thus it is rare that even very basic information is available about smoking and alcohol intake, both of which could be confounding factors. ${ }^{16}$ The notes did, however, allow us to ascertain information about steroid preparations similar to oral contraceptives taken for noncontraceptive reasons, usually menorrhagia, and combine this with the exposure to oral contraceptives. Both cases and controls were exposed to various other hormones, summarised in table $\mathrm{V}$, usually taken for menstrual problems, for infertility, or to suppress lactation. Of the two women who had used the anti-inflammatory corticosteroid prednisolone, one had hepatocellular carcinoma and had been prescribed the drug for almost 12 years after a diagnosis of Crohn's disease, and the other had cholangiocarcinoma and had used the drug for three and a half years for a sarcoidosis. The two women excluded from the study because of chronic active hepatitis (and not included in table V) had also both received long term treatment with prednisolone before developing hepatocellular carcinoma, one for 10 years and the other for 14 years. It is obviously $m$ difficult to draw any conclusions about the role of prednisolone in liver cancer, but, as has been reported, ${ }^{18}$ it may increase susceptibility to the development of cancer.

It is clear that although our results show a highly significant effect of long term use of oral contraceptives on the development of hepatocellular carcinoma, the small number of cases and the problems in study design mean that they should be treated with great caution. In particular, the magnitude of the effect must be extremely imprecise. It now seems beyond doubt, however, that there is an interaction between steroid hormones and liver cells potentially leading to the formation of tumours. In addition to the well established relation between oral contraceptive steroids and benign liver adenoma, ${ }^{19} 20$ it also seems likely that men using anabolic steroids are at increased risk of malignancy in the liver. ${ }^{21-24}$ Evidence from experiments in rodents also suggests that steroids may act as promoters in the liver ${ }^{25-28}$ and that this, rather than any direct genotoxic effects, probably explains an aetiological relation with formation of tumours. Steroids can also induce cholestasis, which could increase exposure of the liver to carcinogenic bile acids. ${ }^{29} 30$

Liver cancer in young women is still an exceptionally rare disease in the United Kingdom, but our results suggest that a substantial proportion of the few cases that do occur in non-cirrhotic livers are attributable to the use of oral contraceptives. Furthermore, if oral contraceptives have some kind of multiplicative interaction with other established risk factors for hepatocellular carcinoma, such as hepatitis B infection or exposure to aflatoxin, then the impact of oral contraceptives in those parts of the world where hepatocellular carcinoma is common would be considerable. Further studies of the relation between the use of oral contraceptives and hepatocellular carcinoma are therefore needed, particularly in developing countries, where the prevalence of infection with hepatitis B virus is high.

We thank staff at the Office of Population Censuses and Surveys for providing us with the draft death entries; the hundreds of general practitioners, hospital records officers, and family practitioner committee administrators, who helped us by identifying patients and completing our questionnaires; Dr S Brown, department of community medicine and general practice, Oxford, for helping to extract from general practitioners' records sent to us; and Miss C Bates for secretarial help.

\section{References}

1 Gala KV, Griffin TW. Hepatomas in young women on oral contraceptives: report of two cases and review of the literature. $\mathcal{F}$ Surg Oncol 1983;22:11-4

2 Vana J, Murphy GP. Primary malignant liver tumors-association with oral contraceptives. $\mathrm{NY}$ State $\mathcal{F}$ Med 1979;79:321-5.

3 Mays ET, Christopherson $\mathbf{W}$. Hepatic tumours induced by sex steroids. Semin Liver Dis 1984;4:147-57.

4 Goodman ZD. Ishak KG. Hepatocellular carcinoma in women: probable lack of etiologic association with oral contraceptive steroids. Hepatolog: 1982;2:440-4.

Forman D, Doll R, Peto R. Trends in mortality from carcinoma of the liver and the use of oral contraceptives. Br $\mathcal{Z}$ Cancer 1983;48:349-54.

6 Neuberger J, Portmann B, Nunnerley HB, Laws JW', Davis M, William R. Oral contraceptiveassociated liver tumours: accurrence of malignancy and difficulties in diagnosis. Lancet $1980 ; 1 \cdot 273-6$.

7 Davis $M$, Portmann B, Searle $M$, Wright $R$, Williams $R$. Histological evidence of carcinoma in a hepatic tumour associad with oral contraceptives. Br Med 7 1975; iv:496-8.

8 Klatskin G. Hepatic tumours: possible relation to use of oral contraceptives. Gastroenterologv

9 Anonvmous. IARC monographs on the evaluation of the carcinogenic risk of chemicals to humans. IARC Monogr Eval Carcinog Risk Chem Hum [S uppl] 1982;4.

0 Henderson BE, Preston-Martin S, Edmondson HA, Peters RL, Pike MC. Hepatocellular carcinoma associated with use of oral contraceptives. $B r \mathcal{F}$ Cancer 1983;48:437-40.

Neuberger J, Forman D, Doll R, Williams R. Oral contraceptives and hepatocellular carcinoma. BrMed F 1986;292:1355-7.

12 Gordis L. Should dead cases be matched to dead controls. Am f Epidemiol 1982;115:1-5.

3 McLaughlin JK, Blot W'J, Mehl ES, Mandel JS. Problems in the use of dead controls in casecontrol studies. Am f Epidemiol 1985;121:131-9 and 122:485-94.

14 Adam SA, Thorogood M, Mann Jl. Oral contraception and myocardial infarction revisited: the effects of new preparations and prescribing patterns. Br 7 Obstet Gynaecol 1982;88:838-43.

15 Coulter A, Vessey M, McPherson K, Crossley B. The ability of women to recall their oral con

hepatitis B negaiv

Hardell L, Bengtss liver cancer with special regard to alcohol, organic solvents and acute intermittent porphyria-
an epidemiological investigation. $B r \mathcal{F}$ Cancer 1984;50:389-97.

18 Lee FL, Murray SM, Prior J, Shreave DR. Primary liver cell cancer occurring in association with \\ $\stackrel{2}{c}$ , . .

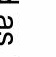 , , . . ,

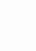


Crohn's disease treated with prednisolone and azathioprine. Hepatogastroenterology 1983;30: 188.

19 Edmondson HA, Henderson B, Benton B. Liver cell adenomas associated with the use of oral contraceptives. N Engl f Med 1976;294:470-2.

20 Rooks HJB, Ory HW, Ishak KG, et al. Epidemiology of hepatocellular adenoma-the role of oral contraceptive use. fAMA 1979;242:644-8.

21 Berstein MS, Hunter RL, Yochnin S. Hepatoma and peliosis hepatitis developing in a patient with Fanconi's anemia. N Engl I Med 1971;284:1135-6.

22 Johnson FL, Feogler JR, Lerner KG, et al. Association of androgenic-anabolic steroid therapy with development of hepatocellular carcinoma. Lancet 1972;iv:1273-6.

23 Fannell GC, Uren RF, Joshua DE, Perkins KW, Baird PJ, Kronenberg H. Androgen induced hepatoma. Lancet 1975;i:430-1.

24 Westaby D, Ogle SJ, Paradinas FJ, Randell JB, Murray-Lyon IM. Liver damage from long-term methyltestosterone. Lancet 1977; ii:261-3.
25 Taper $\mathbf{H}$, de Gerlache J, Lans $\mathbf{M}$, Preat V, Roberfroid $\mathbf{M}$. Estrogens and primary liver tumours. In: Hormones and sexual factors in human cancer aetiology. Amsterdam: Elsevier (in press).

$26 \mathrm{Li} \mathrm{JJ}, \mathrm{Li} \mathrm{SA}$. High incidence of hepatocellular carcinomas after synthetic estrogen administration in Syrian golden hamsters fed $\alpha$-naphthoflavone: a new tumour model. $7 N C I$ 1984;73:543-7.

27 Wanless IR, Medline A. Role of estrogens as promoters of hepatic neoplasia. Lab Invest $1982 ; 46: 313-20$

28 Yager JD, Yager R. Oral contraceptive steroids as promoters of hepato-carcinogenesis in female Sprague-Dawley rates. Cancer Res 1980;40:3680-5.

29 Adlercreutz $\mathrm{H}$, Tenhunen $\mathrm{R}$. Some aspects of the interaction between natural and synthetic female sex hormones and the liver. Am $\mathcal{F}$ Med 1970;49:630-48.

30 Goldfarb S. Sex hormones and hepatic neoplasia. Cancer Res 1976;36:2584-6.

(Accepled 6 May 1986)

\section{SHORT REPORTS}

\section{Are families of diabetic children adequately taught?}

Education is an integral part of caring for patients with diabetes. We report a study of the knowledge of the families of children with diabetes attending five clinics in the north of England.

\section{Subjects, methods, and results}

All parents and patients over 11 years of age attending five children's diabetic clinics were invited to complete a multiple choice questionnaire that had 83 correct answers and to take a practical test of drawing up an insulin mixture and testing blood and urine. The children's haemoglobin $A_{1}$ and $C$ peptide concentrations were measured and their dietary intakes estimated from a three day diary. ' The data were analysed using SPSSX to calculate Pearson's $r$ correlation coefficients, partial correlation coefficients, $t$ test, and analysis of variance. $^{2}$

Multiple choice questionnaires were completed by 96 children, 152 mothers, and 62 fathers from 170 families ( $75 \%$ of those asked). Those who declined tended to have older children and to come from lower socioeconomic groups.

There was a significant relation between parents' scores in the multiple choice questionnaire and the children's haemoglobin $A_{1}$ concentrations after controlling for $C$ peptide values $(r=-0 \cdot 28 ; p<0 \cdot 01)$. The scores also were related to socioeconomic group, father's employment state, and the age at which the child's diabetes had been diagnosed (table). The mothers', but not the fathers', scores

Multiple choice questionnaire scores in children and mothers

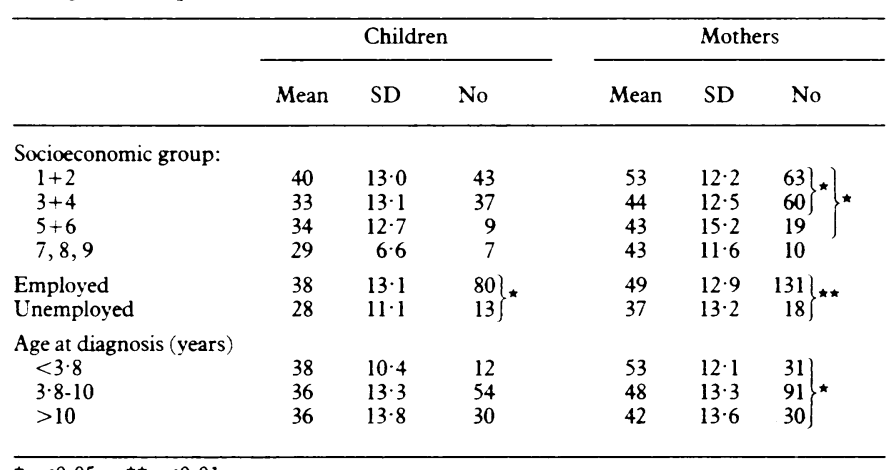

${ }^{\star} p<0.05 . \quad{ }^{\star \star} p<0.01$

correlated with some aspects of the children's dietary intake: compliance with carbohydrate prescription $(\mathbf{r}=0.27 ; \mathrm{p}<0.01)$, fibre expressed as $\mathrm{g} / \mathrm{MJ}(\mathbf{r}=0.34$; $p<0.01)$, and proportion of energy from sugars $(r=0.16 ; p<0.05)$ but not from fat. There was no relation between questionnaire score and duration of diabetes. Ninety four children showed fat hypertrophy at injection sites and 91 used only one or two sites; $15 \%$ of subjects made errors when performing the blood test and $21 \%$ made errors in the urine test; none of these faults were related to scores in the questionnaire. A total of $14 \%$ of subjects, however, made an error in drawing up the insulin, and mothers in these families had lower scores in the questionnaire (mean (SD) 40 (12) compared with $49(13) ; \mathrm{p}<0.05$ ). Similarly, $37 \%$ of children left 10 minutes or less between the time of injection and meal, and their mothers scored lower than those who left more than 10 minutes (44 (15) and 50 (12) respectively; $p<0.05)$. The mean scores in families who were active members of the British Diabetic Association were higher than those of non-members ( 53 $(11.4)$ and $39(12.7) ; p<0.05)$; the mean score of inactive members of the association was intermediate.

\section{Comment}

Although a multiple choice questionnaire has limitations as a tool for assessing knowledge, we found scores related to several outcome variables: diet, technique and timing of insulin injections, and haemoglobin $A_{1}$ values. This supports studies showing benefits of improved education. ${ }^{3+}$ Large gaps in knowledge about diabetes and poor performance of routine tasks, apparently sometimes despite knowledge, were detected. Furthermore, knowledge did not seem to improve with duration of the disease even in this study of regular clinic attenders. At the time of the study the only educational method used was individual teaching at diagnosis and in the clinic, though parents were encouraged to join the British Diabetic Association. The relation between membership and scores may reflect motivation but suggests that the association is an effective source of information.

Objective tests of knowledge should be part of regular review procedures, and teaching methods complementary to clinic visits should be introduced.

We acknowledge the generous support and encouragement of colleagues whose patients we studied-Dr F W Alexander, Dr A P Kenna, Dr M Oo, Dr R C Dias, Dr I H Grant, Dr G P Wyatt, Dr W F Kelly, and Dr D Carr. We also thank Dr G Lawson, Dr H Coleman, and Angela Stephenson for help in collecting data.

1 Hackett AF, Court S, McCowen C, Parkin JM. A dietary survey of diabetics. Arch Dis Child 1986;61:67-71

2 Norusis MJ. SPSSX introductory statistics guide. New York: McGraw-Hill Book Company, 1983.

3 Kohler E, Horwitz LS, Milan D. A developmentally staged curriculum for teaching self-care to the child with insulin-dependent diabetes mellitus. Diabetes Care 1983;5:300-4

4 Mulhauser V, Jorgens M, Berger M, et al. Bicentric evaluation of a teaching and treatment programme for (insulin dependent) diabetic patients: improvements of metabolic control and programme for (insulin dependent) diabetic patients: improvements of metabolic
other measures of diabetes care for up to 22 months. Diabetologia 1983:25:470-6.

(Accepled 21 February 1986

Children's Department, Royal Victoria Infirmary, Newcastle upon Tyne NE1 4LP

C MCCOWEN, MRCP, DCH, consultant paediatrician

A F HACKETT, MPHIL, SRD, research fellow

S COURT, MB, MRCP, consultant paediatrician

J M PARKIN, MD, FRCP, consultant paediatrician

Correspondence to: Dr Parkin.

\section{Localised intratesticular abscess complicating epididymo-orchitis: the use of scrotal ultrasonography in diagnosis and management}

Although epididymo-orchitis usually responds satisfactorily to antibiotic treatment, it may progress to suppurative necrosis of the testis in about $5.5 \%{ }^{1}$ This complication, preceded by the imminent discharge of pus through the scrotal wall, inevitably results in orchidectomy. Non-resolution of epididymo-orchitis may also manifest as recurrent scrotal pain with swelling and cause considerable morbidity. Under these circumstances management may be difficult. The presence of an indurated intrascrotal mass may mimic the signs of a testicular tumour, ${ }^{2}$ which in the absence of 